\title{
STUDY THE POTENTIAL ANTIOXIDANT EFFECT OF VITAMIN D3 SUPPLEMENTATION ON THE LEVEL OF EXTRACELLULAR SUPEROXIDE DISMUTASE IN ASTHMATIC PATIENTS
}

\author{
RASHA SAADI ABBAS ${ }^{1}$, MANAL KHALID ABDULRIDHA ${ }^{1 *}$, MOSTAFA ABDALFATAH SHAFEK ${ }^{2}$ \\ ${ }^{1}$ Department of Clinical Pharmacy, College of Pharmacy, Al-Mustansiriyah University, Baghdad, Iraq. ${ }^{2}$ Department of Internal Medicine, \\ Al-Yarmouk Teaching Hospital, Baghdad, Iraq. Email: pharm.mrdha@uomustansiriyah.edu.iq
}

Received: 31 March 2017, Revised and Accepted: 13 April 2017

\section{ABSTRACT}

Objective: This study was designed to evaluate the potential antioxidant effect of vitamin $\mathrm{D}_{3}$ supplementation in chronic asthma patients.

Methods: A total of 44 candidate patients were diagnosed with asthma allocated as Group 1 includes 20 patients assigned to receive conventional therapy for asthma and Group 2 includes 24 patients assigned to receive conventional therapy for asthma plus 2000 IU vitamin $\mathrm{D}_{3}$ tablet for 3-month period. Furthermore, 30 apparently healthy subjects were included in the study as a control group. Pulmonary function test, serum 25-hydroxy vitamin D levels, serum extracellular superoxide dismutase (SOD3) levels were measured before and after 3 months therapy.

Results: The mean forced expiratory volume in 1 second (FEV1) both the measured and the percentage of predicted value showed a highly significant increase after 3 months treatment compared to pre-treatment value in both study groups $(\mathrm{p}<0.01)$. When compared to pre-treatment value, there was no significant increase in forced expiratory volume in one second to forced vital capacity ratio (FEV1/FVC) in Group 1 (p>0.05), nevertheless, Group 2 showed highly significant increase after 3 months ( $<<0.01$ ). Approximately, 90-96\% of adult asthmatic patients revealed vitamin $\mathrm{D}$ deficiency $(<20 \mathrm{ng} / \mathrm{ml})$. Post-treatment with adjuvant vitamin $\mathrm{D}_{3}$ therapy, $25 \%$ of patients obtained acceptable level of vitamin D sufficiency ( $\left.\geq 30 \mathrm{ng} / \mathrm{ml}\right)$. After 3 months of the treatment, Group 1 patients showed a significant decrease in mean SOD3 level compared to pre-treatment level $(\mathrm{p}<0.05)$, while Group 2 patients showed a significant increase in mean SOD3 level compared to pre-treatment level $(\mathrm{p}<0.05)$.

Conclusion: Most of the asthmatic patients revealed vitamin D deficiency and supplementation with vitamin D3 reduce oxidative stress burden in those patients.

Keywords: Asthma, Pulmonary function test, Vitamin D status, Antioxidant marker.

(C) 2017 The Authors. Published by Innovare Academic Sciences Pvt Ltd. This is an open access article under the CC BY license (http://creativecommons. org/licenses/by/4. 0/) DOI: http://dx.doi.org/10.22159/ajpcr.2017.v10i7.18816

\section{INTRODUCTION}

Asthma is a chronic inflammatory disorder of the airways, and this inflammation causes recurrent episodes of wheezing, chest tightness, breathlessness, and coughing, especially at night or early morning [1]. There is an increased oxidative stress in asthma caused by inflammatory cells, such as macrophages and eosinophils which produce reactive oxygen species (ROS) [2]. Increased oxidative stress in asthma is confirmed by the increased concentrations of 8-isoprostane (which is a product of oxidized arachidonic acid) and ethane (which is a product of lipid peroxidation) in the exhaled air of asthmatic patients $[3,4]$. Oxidative stress increment is associated with disease severity, exaggerate the inflammatory response, and decrease responsiveness to corticosteroids [2]. Many cells of the respiratory tract, including macrophages and epithelial cells, produce antioxidants enzymes such as superoxide dismutase (SOD), and catalase [5].

Oxidative stress results from excessive exposure to reactive oxygen and nitrogen species due to inflammation or environmental air pollution and cigarette smoke which leads to damage of proteins, lipids, and DNA [6]. The rapid reaction of nitric oxide with ROS and the specific localization of antioxidant enzymes, such as superoxide in the lung suggest that antioxidant enzymes might also function as cell signaling agents or regulators of cell signaling [6]. ROS could exacerbate asthma via effects on airway smooth muscle and mucin secretion. The first effect, ROS decrease $\beta$-adrenergic function in lungs, and sensitize airway muscles to acetylcholine inducing contraction, activates mitogen-activated kinases in tracheal myocytes and stimulates tracheal smooth muscle contraction [6]. The second effect, ROS have been reported to stimulate mucin secretion [7].
The primary defense against ROS is endogenous antioxidants, which include the families of SOD, catalase, glutathione peroxidase, glutathione S-transferase, and thioredoxin with their subtypes, for example, the three mammalian SOD are cytosolic (SOD1, copper-zinc SOD), mitochondrial (SOD2, manganese SOD), and extracellular SOD (EC-SOD, SOD3), and two thioredoxins; the cytosolic (Trx1) and the mitochondrial (Trx2) one [6,8]. SOD activity is reduced in the asthmatic airway [9], mainly during exacerbation with enhanced production of oxygen radicals by inflammatory cells [10], where its activity in the lung is related to airway hyperreactivity and airflow limitation [9]. EC-SOD, SOD3 is the primary EC-SOD enzyme and is highly expressed in human lungs approximately 8 times that of the liver, 6 times that of the brain, 2-3 times that of the heart, and 1-2 times that of the kidney [11].

Many studies point out that SOD activity might play a role in asthma. First, a study showed that there was a reduction of airway hyperresponsiveness in rabbits after intravenous administration of polyethylene glycol conjugated SOD suggest that increased SOD activity may attenuate asthma [12]. The second one, after antigen challenge, airway macrophages from individuals with asthma produce more superoxide anion than control subjects [13]. Third, a study showed that SOD activity is decreased in asthmatic patients cells of bronchoalveolar lavage and brushings [14]. Another study showed that asthmatic patients who are responsive and controlled with inhaled corticosteroids and long-acting $\beta 2$-agonists had higher lipid peroxide levels when compared with healthy controls [15].

Vitamin D is an essential nutrient that is usually obtained through exposure to sunlight, and secondarily through diet and dietary supplements [16]. 
Many studies identified the complex role of vitamin D in immune responses regulation. Various immune cell types express VDRs, including activated T-lymphocyte, $\beta$-cells, macrophages, and dendritic cells $[16,17]$. Expression of $1 \alpha$-hydroxylase (the enzyme responsible for the production of active form of vitamin D) by cells at extra-renal sites improve both the capacity for extra-renal synthesis of the active form of vitamin $\mathrm{D}$ and to modulate innate and adaptive immune function at these sites [16]

This study was designed to evaluate the potential antioxidant effect of vitamin $\mathrm{D}_{3}$ supplementation on the level of EC-SOD or SOD3 in patients with chronic asthma.

\section{MATERIALS AND METHODS}

\section{Study design}

This is a prospective randomized-controlled open-label interventional study to evaluate the antioxidant effect of vitamin $D_{3}$ in asthma patients.

\section{Patients}

A total of 44 candidate patients were diagnosed with asthma during their visit to hospital. The patients were under the supervision of pulmonary specialist and were treated according to clinical practice guideline and disease severity.

The Local Clinical Research Ethics Committee, in accordance with Helsinki Declaration 1998, approved the study protocol and all subjects gave written informed consent to participate in the study. The eligible patients and subjects were allocated into three main groups:

- Group 1: Include 20 patients who have diagnosed with asthma are assigned to receive conventional therapy for asthma according to disease stage and severity for 3-month period

- Group 2: Include 24 patients who have diagnosed with asthma are assigned to receive conventional therapy for asthma according to disease stage and severity plus 2000 IU vitamin $\mathrm{D}_{3}$ fast dissolve mini tablet (Natrol, USA) for 3-month period

- Control group: Include 30 apparently healthy control subjects

\section{Pulmonary function test (PFT) using spirometry}

It was measured using Spiro Air (volumetric PFT) (Medisoft, Belgium) in which forced expiratory volume in 1 second (FEV1) both the measured and percentage of predicted value in addition to FEV1/forced vital capacity (FEV1/FVC) ratio were measured before and after 3 months therapy for both Groups 1 and 2 patients.

\section{Specimens collection}

To $5 \mathrm{ml}$ of venous blood were drawn using a plastic disposable syringe and collected in disposable plain tube (gel and clot activator) and was allowed to clot and separated by centrifuge at speed of $3000 \mathrm{rpm}$ for 10 minutes. The serum samples were stored at $-40^{\circ} \mathrm{C}$ until the time of examination.

\section{Serum 25-hydroxy (25[OH]) vitamin D level measurement}

It was determined using commercial enzyme-linked immunosorbent assay (ELISA) kit (Euroimmun, Germany), measured at baseline in Group 1, Group 2 patients and healthy control group and after 3 months treatment in Groups 1 and 2 patients.

\section{Serum EC-SOD, SOD3}

It was determined using commercial ELISA kit (Elabscience Biotechnology, China) measured before and after 3 months therapy for both Groups 1 and 2 patients.

\section{Statistical analysis}

The Statistical Analysis System Minitab 16.1 (2010) was used. Data presented as mean \pm standard deviation. Pearson Chi-square test was utilized to detect significant differences among demographic variables, while paired t-test was used to compare between pre- and posttreatment results; two-sample t-test was used to compare pre- or posttreatment between Groups 1 and 2. Analysis of variance was utilized to compare between the studied parameters among different patient groups.

NS: No significant differences $(\mathrm{p}>0.05)$, ${ }^{*}$ significant difference $(\mathrm{p}<0.05)$, $* *$ highly significant difference $(\mathrm{p}<0.01)$.

\section{RESULTS}

\section{Patients demographic and disease characteristics}

The patient demographic and disease characteristic for 74 subjects including 53 female (71.6\%) and 21 male gender (28.4\%) with no significant statistical difference was found among study groups in respect to both genders $(p>0.05)$ (Table 1$)$. The age range for the groups where between 14 and 71 years with the mean age of the study groups was as follows: Group 1 patients (40.75 \pm 17.31$)$ years, and Group 2 patients $(41.4 \pm 13.6)$ years, and control group $(45.86 \pm 15.83)$ years with no statistically significant difference was found among study groups with respect to age ( $p>0.05)$. Positive family history of asthma was found in $65 \%$ and $58.3 \%$ of Groups 1 and 2 patients, respectively, while negative family history was found in $35 \%$ and $41.7 \%$ for Groups 1 and 2 patients, respectively, with no statistically significant difference between these groups $(\mathrm{p}>0.05)$. Considering the patients residence there were $85 \%$ of Group 1 patients versus $79.2 \%$ of Group 2 patients were urban, and $15 \%$ of Group 1 patients versus $20.8 \%$ of Group 2 patients were rural with no significant statistical difference between both groups $(\mathrm{p}>0.05)$. The duration of the disease for Groups 1 and 2 patients, respectively, were as follows: $80 \%$ versus $62.5 \%$ for $<20$ years, $15 \%$ versus $25 \%$ for $21-40$ years duration, $5 \%$ versus $12.5 \%$ for $41-60$ years duration, with a mean of $12.8 \pm 11.2$ years for Group 1 patients and 20.2 \pm 15.4 years for Group 2 patients, respectively, and no statistically significant difference was found between both groups in respect to duration of the disease ( $\mathrm{p}>0.05)$.

Effect of conventional therapy alone and in combination with vitamin $D_{3}$ supplement on PFT using spirometry in asthmatic patients

The mean FEV1 both the measured and the percentage of predicted value showed no significant difference at baseline and after 3 months between the study groups ( 1 and 2 ) ( $>>0.05$ ) while highly significant increase was noticed after 3 months treatment compared to pretreatment value for both Groups 1 and 2 patients $(\mathrm{p}<0.01)$. The mean FEV1/FVC ratio showed a significant difference at baseline level between Groups 1 and 2 ( $p<0.05)$, but no significant differences was found after 3 months between both groups $(\mathrm{p}>0.05)$. There was no significant increase in (FEV1/FVC) ratio after 3 months in Group 1 when compared to pre-treatment value $(p>0.05)$, nevertheless, Group 2 showed highly significant increase after 3 months treatment compared to pre-treatment value $(\mathrm{p}<0.01)$ (Table 2).

Effect of conventional therapy alone and in combination with vitamin $D_{3}$ supplement on endogenous vitamin $D$ status in asthmatic patients treated for 3 months compared with healthy control group

The endogenous vitamin D status at a baseline in 18 patients in Group 1, 23 patients in Group 2, 24 subjects in control group were considered as vitamin D deficiency $(<20 \mathrm{ng} / \mathrm{ml})$ with a statistically significant differences were seen among study groups $(\mathrm{p}<0.05)$. On the other hand, 2 patients in Group 1, 1 patient in Group 2, 4 subjects in control group had vitamin D insufficiency (20-29 ng/ml) with no statistically significant differences were found among study groups ( $p>0.05)$. Only 2 subjects in control group were found to have a vitamin D sufficiency ( $\geq 30 \mathrm{ng} / \mathrm{ml}$ ) (Table 3 ). After 3 months, the endogenous vitamin D status showed deficiency $(<20 \mathrm{ng} / \mathrm{ml})$ in 15 patient of Group 1 and 8 patient of Group 2 with highly significant differences between both groups $(\mathrm{p}<0.01)$. Vitamin D insufficiency $(20-29 \mathrm{ng} / \mathrm{ml})$ was found in 5 patients 
Table 1: Patients demographic and disease characteristics

\begin{tabular}{|c|c|c|c|c|}
\hline \multirow[t]{2}{*}{ Variables } & \multicolumn{4}{|l|}{ Study groups } \\
\hline & Group 1 & Group 2 & Control group & p value \\
\hline Age (year) & $40.75 \pm 17.31^{\text {aNs }}$ & $41.4 \pm 13.6^{\mathrm{aNS}}$ & $45.86 \pm 15.83$ & $0.890^{\mathrm{bNS}}$ \\
\hline Gender & N (\%) & N (\%) & N (\%) & \\
\hline Female & $13(65.0)$ & $20(83.3)$ & $20(66.7)$ & $0.299^{\mathrm{NS}}$ \\
\hline Male & $7(35.0)$ & $4(16.7)$ & $10(33.3)$ & \\
\hline Total & $20(100)$ & $24(100)$ & $30(100)$ & \\
\hline \multicolumn{5}{|c|}{ Family history } \\
\hline Positive & $13(65.0)$ & $14(58.3)$ & - & \\
\hline Negative & $7(35.0)$ & 10 (41.7) & - & $0.651^{\mathrm{NS}}$ \\
\hline \multicolumn{5}{|l|}{ Residence } \\
\hline Urban & $17(85.0)$ & $19(79.2)$ & - & $0.617^{\mathrm{NS}}$ \\
\hline Rural & $3(15.0)$ & $5(20.8)$ & - & \\
\hline \multicolumn{5}{|c|}{ Duration of the disease (year) } \\
\hline$\leq 20$ & $16(80.0)$ & $15(62.5)$ & - & $0.072^{\mathrm{NS}}$ \\
\hline $21-40$ & $3(15.0)$ & $6(25.0)$ & - & \\
\hline $41-60$ & $1(5.0)$ & $3(12.5)$ & - & \\
\hline$\geq 61$ & None & None & - & \\
\hline
\end{tabular}

Data presented as mean \pm SD. ${ }^{a}$ Comparison with control group. ${ }^{b}$ Comparison between Group 1 and 2. NS: No significant differences (p $>0.05$ ). SD: Standard deviation

Table 2: Effect of conventional therapy alone and in combination with vitamin $D_{3}$ supplement on PFT using spirometry in asthmatic patients treated for 3 months

\begin{tabular}{llll}
\hline Variables & \multicolumn{2}{l}{ Study groups } & \\
\cline { 2 - 4 } & Group 1 & Group 2 & p value \\
\hline FEV1(L) Meas. & & & \\
Pre-treatment & $1.584 \pm 0.871$ & $1.189 \pm 0.514$ & $0.084^{\mathrm{NS}}$ \\
Post-treatment & $2.091 \pm 1.013$ & $1.753 \pm 0.674$ & $0.212^{\mathrm{NS}}$ \\
p value & $0.009^{* *}$ & $0.000^{* *}$ & - \\
FEV1 (\% Pred.Val.) & & & \\
Pre-treatment & $50.90 \pm 16.04$ & $43.92 \pm 20.36$ & $0.210^{\mathrm{NS}}$ \\
Post-treatment & $68.85 \pm 14.93$ & $63.04 \pm 20.68$ & $0.287^{\mathrm{NS}}$ \\
p value & $0.003^{* *}$ & $0.000^{* *}$ & - \\
FEV1/FVC (\%) & & & \\
Pre-treatment & $74.37 \pm 13.25$ & $63.62 \pm 14.33$ & $0.013^{*}$ \\
Post-treatment & $78.30 \pm 12.58$ & $71.45 \pm 13.15$ & $0.086^{\mathrm{NS}}$ \\
p value & $0.341^{\mathrm{NS}}$ & $0.005^{* *}$ & - \\
\hline
\end{tabular}

Data presented as mean \pm SD, FEV1(L): Forced expiratory volume in 1 second in liter, FEV1/FVC: Forced expiratory volume in one second/forced vital capacity ratio, \% Pred.Val.: Percentage of predicted value, Meas.: Measured value. NS: No significant differences $(\mathrm{p}>0.05)$, *significant difference $(\mathrm{p}<0.05)$, $* *$ highly significant difference $(\mathrm{p}<0.01)$. PFT: Pulmonary function test, SD: Standard deviation

Table 3: Effect of conventional therapy alone and in combination with vitamin $D_{3}$ supplement on endogenous vitamin $D$ status in asthmatic patients treated for 3 months compared with healthy control group

\begin{tabular}{lllll}
\hline Variables & \multicolumn{2}{l}{ Study groups } & \\
\cline { 2 - 5 } & Group 1 & Group 2 & $\begin{array}{l}\text { Control } \\
\text { group }\end{array}$ & p value \\
& & & & \\
\hline Endogenous vitamin D level (ng/ml) & & & \\
Pre-treatment & & & & \\
Deficiency (<20) & $18(90)$ & $23(96)$ & $24(80)$ & $0.015^{*}$ \\
Insufficiency (20-29) & $2(10)$ & $1(4)$ & $4(13)$ & $0.623^{\mathrm{NS}}$ \\
Sufficiency ( $\geq 30)$ & $0(0)$ & $0(0)$ & $2(7)$ & - \\
Total & $20(100)$ & $24(100)$ & $30(100)$ & - \\
Post-treatment & & & & \\
$\quad$ Deficiency $(<20)$ & $15(75)$ & $8(33)$ & - & $0.009^{* *}$ \\
Insufficiency (20-29) & $5(25)$ & $10(42)$ & - & $0.472^{\mathrm{NS}}$ \\
Sufficiency $(\geq 30)$ & $0(0)$ & $6(25)$ & - & - \\
Total & $20(100)$ & $24(100)$ & - & - \\
\hline
\end{tabular}

Data presented as N (\%), endogenous vitamin D measured as (25-0H

vitamin D). NS: No significant differences ( $p>0.05)$, *significant

difference $(\mathrm{p}<0.05)$, **highly significant difference ( $\mathrm{p}<0.01) .25-0 \mathrm{H}$ : 25-hydroxy of Group 1 and 10 patients of Group 2 with no significant differences between both Group 1 and Group 2 ( $>>0.05$ ). Only 6 patients of Group 2 found to have vitamin D sufficiency ( $\geq 30 \mathrm{ng} / \mathrm{ml}$ ) after 3 months treatment.

Effect of conventional therapy alone and in combination with vitamin $D_{3}$ supplement on EC-SOD, SOD3 level in asthmatic patients There was a highly significant differences in the mean SOD3 levels at baseline between both Groups 1 and 2 patients $(\mathrm{p}<0.01)$, and no significant differences was seen post-treatment between both study groups $(p>0.05)$ (Table 4). After 3 months of the treatment, Group 1 patients showed a significant decrease in mean SOD3 level compared to pre-treatment level $(\mathrm{p}<0.05)$. On the other hand, Group 2 patients showed a significant increase in mean SOD3 level compared to pre-treatment level $(\mathrm{p}<0.05)$.

\section{DISCUSSION}

Asthma is one of the most common chronic diseases and considered a major public health problem worldwide [18], and the exact mechanism of vitamin D in oxidative stress and asthma exacerbation remains unclear [19]. Vitamin D might play either preventive or protective role against the development of asthma, effective to be a good candidate as an adjuvant therapy [20].

With reference to the results in this study, highly significant increase in both measured and percentage of predicted value of FEV1 in both study groups after 3 months treatment when compared to pre-treatment value suggesting that this improvement was due to conventional therapy rather the effect of vitamin $\mathrm{D}_{3}$ supplementation. On the other hand, highly significant increase in the ratio of FEV1/FVC in Group 2 after 3 months treatment with vitamin $\mathrm{D}_{3}$ supplementation when compared to Group $1(\mathrm{p}<0.01)$.

The FEV1 is generally considered as efficacy parameters in asthma clinical trials in which patient education increased the FEV1 values in the asthmatic patients due to a better practice followed in using the medications [21]. Tamašauskienè et al. showed no correlations between vitamin D levels and lung function (FEV1, FEV1/FVC) while an inverse positive correlation was noticed between vitamin $\mathrm{D}$ level and FEV1/FVC in asthmatic smokers [22]. Columbo et al. found no significant association between serum vitamin D and spirometric values even in subjects with lower FEV1\% (<70\%) and after 12 weeks treatment with 2000 IU vitamin $\mathrm{D}_{3}$ supplementation [23]. In addition, Nageswari et al. investigated the addition of 1000 IU of vitamin $\mathrm{D}_{3}$ to conventional therapy when compared to conventional therapy alone on PFT; he found that patients in both groups had a significant 
Table 4: Effect of conventional therapy alone and in combination with vitamin $D_{3}$ supplement on EC-SOD, SOD3 level in asthmatic patients treated for 3 months

\begin{tabular}{llll}
\hline Variable & Study groups & & \\
\hline SOD $_{3}(\mathbf{n g} / \mathbf{m l})$ & Group 1 & Group 2 & p value \\
\hline Pre-treatment & $105.9 \pm 14.4$ & $54.4 \pm 4.0$ & $0.002^{* *}$ \\
Post-treatment & $73.6 \pm 10.3$ & $78.5 \pm 10.2$ & $0.739^{\mathrm{NS}}$ \\
p value & $0.031^{*}$ & $0.021^{*}$ & - \\
\hline
\end{tabular}

Data presented as mean \pm SD. NS: No significant differences ( $p>0.05$ ),

*significant difference $(\mathrm{p}<0.05)$, **highly significant difference $(\mathrm{p}<0.01)$.

EC-SOD: Extracellular superoxide dismutase, SD: Standard deviation

improvement in percentage of predicted value of FEV1 after 3 months treatment [24].

Many other studies correlate vitamin D status to PFT. Recent study published in China showed that patients with severe asthma exacerbation and vitamin D deficiency had lower FEV1\% and decreased corticosteroid response when compared to vitamin D sufficient asthmatic patients [19]. Another study in asthmatic patients the serum $25(\mathrm{OH})$ vitamin D was positively correlated with FEV1\% predicted and FEV1/FVC ratio [25].

This study showed that at baseline, $90 \%$ of Group 1, 96\% of Group 2, and $80 \%$ of the control group had vitamin D deficiency $(<20 \mathrm{ng} / \mathrm{ml})$. Furthermore, $10 \%$ of Group 1, $4 \%$ of Group 2, and 13\% control group had vitamin D insufficiency $(20-29 \mathrm{ng} / \mathrm{ml})$. Only $7 \%$ of the control group had vitamin D sufficiency $(\geq 30 \mathrm{ng} / \mathrm{ml}$ ). A similar finding had been stated by many studies with the same result on elderly asthmatic patients, where $(79 \%)$ had lower than normal serum vitamin D at baseline [23]. These results confirm that vitamin D deficiency and insufficiency are extremely common in patients with asthma [26], and mostly pronounced in patients with severe and/or uncontrolled asthma [18]. Kamran et al. found a high prevalence of vitamin D deficiency and insufficiency (88.10\%) in adult patients with moderate to severe persistent asthma [27]. Furthermore, Freishtat et al. found a high prevalence of vitamin D deficiency and insufficiency among African-American youth with asthma in Washington, DC [28]. Moreover, another study explained the association between vitamin D level and respiratory outcome in Canadian adult, in this study vitamin D deficiency might be associated with increased risk of current and ever asthma [29].

The severity of asthma control might be correlated with lifestyle and dietary changes as a reverse causal effect (i.e., severe asthma leading to vitamin D insufficiency), which may be attributed to a less time spent outdoors, limited activity, and medication. Another causal effect is that asthma severity is negatively influenced by vitamin D insufficiency that occurred independently of asthma morbidity or control [26]. One study suggested that the daily oral intake of vitamin D in sunlight deprived individuals should exceed $600 \mathrm{IU}$; most probably it should be $1000 \mathrm{IU}$ day to secure a normal level of $25(\mathrm{OH})$ vitamin $\mathrm{D}$ [30].

Recent study found that vitamin $\mathrm{D}$ reduce inflammatory burden in asthmatic patient [31], while other studies have demonstrated alterations in different endogenous antioxidants in patients with asthma which may involve either an increase or a decrease pattern depending on the changes occurring due to a defense response [32]. In this study, the effect of vitamin $\mathrm{D}_{3}$ supplementation on EC-SOD, SOD3 showed a significant increase in SOD3 antioxidant enzyme after 3 months treatment with vitamin $\mathrm{D}_{3}$ supplementation to conventional therapy in Group 2 patients $(\mathrm{p}<0.05)$, meanwhile significant decrease of this enzyme activity after 3 months treatment with conventional therapy alone in Group 1 patients $(p<0.05)$. These result highlighted a potential effect of vitamin $\mathrm{D}_{3}$ in activating this antioxidant enzyme. Highly significant differences in SOD3 level were detected at baseline between asthmatic groups which can be explained by the difference in the severity of the disease at which the patients presented with along with the fact that conventional therapy might failed to control the oxidative level at different steps of treatment.

This study was designed to examine the SOD3 activity in serum for a number of reason; first, blood is considered as an important pool of antioxidant defenses in the body. Second, asthma is an inflammatory disease in which cells are recruited from the peripheral blood into the airways. Third, blood is an easily available source to study the oxidantantioxidant imbalance rather than bronchoalveolar fluid which is obtained through an invasive bronchoscope technique which only be performed in patients with stable asthma and who are likely to show less marked alterations in the oxidant-antioxidant balance observed in a more unstable state [32,33].

Loss of serum SOD activity in asthma may thus reflect a greater magnitude and/or ongoing systemic oxidative stress in patients with asthma with severe airflow limitation, with a consequent greater oxidative modification of SOD systemically in addition to allergentriggered inflammatory pathways may participate in loss of systemic SOD activity, perhaps through increasing oxidative stress [6,34,35], and subsequent inactivation of SOD [8]. Lan et al. found that SOD in vitamin D deficient patients was significantly decreased compared to SOD in vitamin D sufficient patients in severe asthma exacerbation indicated that vitamin D deficiency aggravated the oxidative changes, increased oxidative stress, and DNA damage in severe asthma exacerbation [19], also the ROS levels were significantly decreased in the vitamin D deficient patients treated with methylprednisolone and vitamin $\mathrm{D}_{3}$ compared to that in the vitamin D sufficiency patients treated with methylprednisolone alone [19]. Previous studies showed that SOD activity was lower in asthmatic patients as compared with control, and activity loss was significantly related to airflow limitation suggest that the lower SOD activity in asthma may derive from airway inflammation and injury, cell turnover, and release of inactive SOD $[5,8,32,36]$.

\section{CONCLUSION}

This study revealed that vitamin D reduce oxidative stress burden in asthmatic patients, suggesting that vitamin D plays effective role to be a good candidate as an adjuvant therapy. Further evaluation is needed to explore the potential effect of vitamin D supplementation in acute or chronic asthma using different oxidative markers at different stages of disease severity.

\section{ACKNOWLEDGMENT}

The author would like to thank Mustansiriyah University (www. uomustansiriyah.edu.iq) Baghdad - Iraq for its support in the present work and special thanks to Al-Yarmouk Teaching Hospital for their help in providing the practical platform of this study.

\section{REFERENCES}

1. Self TH, Chrisman CR, Finch CK. Asthma. In: Alldredge BK, Corelli RL, Ernst ME, Guglielmo BJ, Jacobson PA, Kradjan WA, et al. Koda-Kimble and Young's Applied Therapeutics: The Clinical Use of Drugs. $10^{\text {th }}$ ed. Philadelphia, PA: Lippincott Williams and Wilkins; 2013. p. 565-600.

2. Barnes PJ. Pathophysiology of asthma. ERS J 2003;23:84-113.

3. Montuschi P, Corradi M, Ciabattoni G, Nightingale J, Kharitonov SA, Barnes PJ. Increased 8-isoprostane, a marker of oxidative stress, in exhaled condensates of asthmatic patients. Am J Respir Crit Care Med 1999;160(1):216-20.

4. Paredi P, Kharitonov SA, Barnes PJ. Elevation of exhaled ethane concentration in asthma. Am J Respir Crit Care Med 2000;162:1450-4.

5. Rai RR, Phadke MS. Plasma oxidant-antioxidant status in different respiratory disorders. Indian J Clin Biochem 2006;21(2):161-4.

6. Bowler RP, Crapo JD. Oxidative stress in allergic respiratory diseases. J Allergy Clin Immunol 2002;110(3):349-56.

7. Wright DT, Fischer BM, Li C, Rochelle LG, Akley NJ, Adler KB. Oxidant stress stimulates mucin secretion and PLC in airway epithelium via a nitric oxide-dependent mechanism. Am J Physiol 1996;271:L854-61. 
8. Comhair SA, Ricci KS, Arroliga M, Lara AR, Dweik RA, Song W, et al. Correlation of systemic superoxide dismutase deficiency to airflow obstruction in asthma. Am J Respir Crit Care Med 2005;172(3):306-13.

9. Comhair SA, Xu W, Ghosh S, Thunnissen FB, Almasan A, Calhoun WJ, et al. Superoxide dismutase inactivation in pathophysiology of asthmatic airway remodeling and reactivity. Am J Pathol 2005;166(3):663-74.

10. Comhair SA, Bhathena PR, Dweik RA, Kavuru M, Erzurum SC. Rapid loss of superoxide dismutase activity during antigen-induced asthmatic response. Lancet 2000;355:624.

11. Bowler RP, Crapo JD. Oxidative stress in airways: Is there a role for extracellular superoxide dismutase? Am J Respir Crit Care Med 2002;166:S38-43.

12. Assa'ad AH, Ballard ET, Sebastian KD, Loven DP, Boivin GP, Lierl MB. Effect of superoxide dismutase on a rabbit model of chronic allergic asthma. Ann Allergy Asthma Immunol 1998;80(3):215-24.

13. Calhoun WJ, Reed HE, Moest DR, Stevens CA. Enhanced superoxide production by alveolar macrophages and air-space cells, airway inflammation, and alveolar macrophage density changes after segmental antigen bronchoprovocation in allergic subjects. Am Rev Respir Dis 1992;145:317-25.

14. Smith LJ, Shamsuddin M, Sporn PH, Denenberg M, Anderson J. Reduced superoxide dismutase in lung cells of patients with asthma. Free Radic Biol Med 1997;22(7):1301-7.

15. Alzoghaibi MA, Bahammam AS. Lipid peroxides in stable asthmatics receiving inhaled steroids and long-acting beta2-agonists. Respirology 2007;12:439-42.

16. Lange NE, Litonjua A, Hawrylowicz CM, Weiss S. Vitamin D, the immune system and asthma. Expert Rev Clin Immunol 2009;5(6):693-702.

17. Berraies A, Hamzaoui K, Hamzaoui A. Link between vitamin D and airway remodeling. J Asthma Allergy 2014;7:23-30

18. Korn S, Hübner M, Jung M, Blettner M, Buhl R. Severe and uncontrolled adult asthma is associated with vitamin D insufficiency and deficiency. Respir Res 2013;14:25.

19. Lan N, Luo G, Yang X, Cheng Y, Zhang Y, Wang X, et al. 25-hydroxy vitamin D3-deficiency enhances oxidative stress and corticosteroid resistance in severe asthma exacerbation. PLOS One 2014;9(11):e111599.

20. Rajanandh MG, Nageswari AD, Prathiksha G. Effectiveness of vitamin D3 in severe persistent asthmatic patients: A double blind, randomized, clinical study. J Pharmacol Pharmacother 2015;6(3):142-6.

21. Saji SM, Jiju KAJ, Sundaran S. Study on the impact of patient counseling on the quality of life and pulmonary function of asthmatic. Int J Pharm Pharm Sci 2012;4 Suppl 5:300-4.

22. Tamašauskienė L, Gasiūnienė E, Lavinskienè S, Sakalauskas R,
Šitkauskienė B. Evaluation of vitamin D levels in allergic and nonallergic asthma. Med (Kaunas) 2015;51(6):321-7.

23. Columbo M, Panettieri RA Jr, Rohr AS. Asthma in the elderly: A study of the role of vitamin D. Allergy Asthma Clin Immunol 2014;10(1):48.

24. Nageswari AD, Rajanandh MG, Priyanka RK, Rajasekhar P. Effect of vitamin $\mathrm{D}_{3}$ on mild to moderate persistent asthmatic patients: A randomized controlled pilot study. Perspect Clin Res 2014;5(4):167-71.

25. Shaaban MM, Hashem M. Serum 25 hydroxy vitamin D levels in adult asthmatic patients. Eur J Hum Mov 2012;49:946-52.

26. Montero-Arias F, Sedó-Mejía G, Ramos-Esquivel A. Vitamin D insufficiency and asthma severity in adults from Costa Rica. Allergy Asthma Immunol Res 2013;5(5):283-8.

27. Kamran A, Alam SM, Qadir F. Prevalence of vitamin D deficiency and insufficiency among adult asthmatic patients in Karachi. Pak J Pharm Sci 2014;27:2139-44.

28. Freishtat RJ, Iqbal SF, Pillai DK, Klein CJ, Ryan LM, Benton AS, et al. High prevalence of vitamin D deficiency among inner-city African American youth with asthma in Washington, DC. J Pediatr 2010;156(6):948-52.

29. Niruban SJ, Alagiakrishnan K, Beach J, Senthilselvan A. Association between vitamin $\mathrm{D}$ and respiratory outcomes in Canadian adolescent and adults. J Asthma 2015;52(7):653-61.

30. Glerup H, Mikkelsen K, Poulsen L, Hass E, Overbeck S, Thomsen J, et al. Commonly recommended daily intake of vitamin D is not sufficient if sunlight exposure is limited. J Intern Med 2000;247(2):260-8.

31. Abbas RS, Abdulridha MK, Shafek MA. Clinical evaluation of the potential anti-inflammatory effect of vitamin D3 adjuvant therapy for chronic asthma in Iraqi patients. Int $\mathrm{J}$ Pharm Pharm Sci 2017;9(1):139-44

32. Ahmad A, Shameem M, Husain Q. Relation of oxidant-antioxidant imbalance with disease progression in patients with asthma. Ann Thorac Med 2012;7(4):226-32.

33. Nadeem A, Chhabra SK, Masood A, Raj HG. Increased oxidative stress and altered levels of antioxidants in asthma. J Allergy Clin Immunol 2003;111(1):72-8.

34. MacPherson JC, Comhair SA, Erzurum SC, Klein DF, Lipscomb MF, Kavuru MS, et al. Eosinophils are a major source of nitric oxide-derived oxidants in severe asthma: Characterization of pathways available to eosinophils for generating reactive nitrogen species. J Immunol 2001;166(9):5763-72.

35. Wu W, Samoszuk MK, Comhair SA, Thomassen MJ, Farver CF, Dweik RA, et al. Eosinophils generate brominating oxidants in allergen-induced asthma. J Clin Invest 2000;105(10):1455-63.

36. Tekin D, Sin BA, Mungan D, Misirligil Z, Yavuzer S. The antioxidative defense in asthma. J Asthma 2000;37(1):59-63. 